\title{
A Market Equilibrium Supply Chain Model for Supporting Self-Manufacturing or Outsourcing Decisions in Prefabricated Construction
}

\author{
Yanhu Han ${ }^{1}$, Miroslaw J. Skibniewski ${ }^{2,3,4}$ and Lufan Wang ${ }^{5, *}$ \\ 1 School of Economics and Management, Chang'an University, Xi'an 710064, China; hyh15@chd.edu.cn \\ 2 e-Construction Group, Center of Excellence in Project Management, Department of Civil and Environmental \\ Engineering, University of Maryland, College Park, MD 20742, USA; mirek@umd.edu \\ 3 Institute of Theoretical and Applied Informatics, Polish Academy of Sciences, Bałtycka 5, \\ 44-100 Gliwice, Poland \\ 4 Chaoyang University of Technology, 168 Jifeng E. Rd., Wufeng District, Taichung 41349, Taiwan \\ 5 Department of Civil and Environmental Engineering, University of Illinois at Urbana-Champaign, \\ Urbana, IL 61801, USA \\ * Correspondence: lwang105@illinois.edu; Tel.: +1-217-898-6146
}

Received: 17 July 2017; Accepted: 6 November 2017; Published: 10 November 2017

\begin{abstract}
Prefabricated construction is a sustainable alternative to traditional on-site construction methods. However, many challenges still exist in the prefabricated construction process. For example, self-manufacturing or outsourcing decisions are vital to the industrial structure and organization of the prefabricated construction industry, and the company's production and operation decision-making. This paper considers a prefabricated construction supply chain, which is composed of one upstream component manufacturing company and two downstream contractors. The large contractor can get the precast component through self-manufacturing or outsourcing, while the small and medium-sized enterprise (SME) contractor can only buy components from the component manufacturer. A comprehensive game model (Cournot-Stackelberg model) under different decisions, that is, component self-manufacturing or outsourcing, was established. By solving the profit functions of different companies in the prefabricated construction supply chain, the equilibrium solutions of output, price and profit can be achieved. These solutions of equilibrium indicate the optimal decision on the production and operation, and the profit's boundary conditions. After assuming relevant parameters, the profit levels of the companies in the supply chain are analyzed via a dynamic simulation in the changing process of prefabricated construction market size under different behavioral decisions. The conclusions are as follows: (1) the profit levels of all supply chain enterprises and the whole supply chain are increasing with an increase of market size; (2) the downstream contractors and the whole supply chain have a higher profit level under the component self-manufacturing decision, however, on the contrary, the upstream component suppliers get a higher profit level under the component outsourcing decision; (3) the equilibrium output of the SME contractor is reduced under the outsourcing decision of the large contractor, and the SME contractor is at a disadvantage in market competition, which is particularlyfull of risk when the market size is not big enough, but higher profit level can be expected as the market size increases. According to the results of the game-theoreticanalysis and the numerical simulation, managerial implications are put forward from the angles of extensive publicity, mandatory implementation, strengthening industrial chain integration, and intensifying component factory guidance to promote the development of prefabricated construction. Finally, the main problems which need to be studied further in the future are presented.
\end{abstract}

Keywords: prefabricated construction; supply chain; market equilibrium; self-manufacturing decision; outsourcing decision 


\section{Introduction}

The construction industry accounts for significant environmental, social, and economic impacts. Traditional cast-in-situ construction methods have long been criticized for their low productivity, poor cost and safety control, long construction duration, significant amount of resource consumption, and considerable waste production [1]. Sustainable construction is, thus, crucial for creating a healthier built environment and achieving global sustainability targets. Prefabricated construction methods, as a sustainable alternative to the traditional construction methods, have been recognized worldwide. The prefabrication process includes three main steps, namely, manufacturing the structural components in factories, transporting the structural components to construction sites, and assembling the structural components to form a building.

Prefabricated construction methods have shown great potential in improving building quality, shortening construction duration, increasing resource utilization efficiency, reducing construction waste, enhancing health and safety performance, enlarging economies of scale, and so on [2]. For example, Aye et al. [3] found that prefabricated steel building is able to result in $81 \%$ savings in embodied energy and 51\% material savings by mass. Mao et al. [4] found that the project using semi-prefabrication method reduced about 1.1 tons per $100 \mathrm{~m}^{2}$ in greenhouse gas emissions compared with the project using traditional construction methods. Vanke, the largest residential real estate developer in Mainland China, has reported that the construction of Vanke Xinlicheng Project in Shanghai has reduced energy usage by $70 \%$, raw materials usage by $50 \%$, construction waste by $40 \%$, and on-site labor by at least $50 \%$, due to adopting the prefabricated construction methods [5]. Therefore, promoting prefabricated construction is a practical need to change the traditional resource/labor-intensive construction mode towards green built environment and sustainable development.

Prefabrication techniques have been progressively adopted in the construction industry in various countries [6]. For example, an average share of precast concrete systems in the construction industry across the European Union is $20-25 \%$, and the share is even higher in the northern European countries, where the share increases up to $40-50 \%$ [7]. However, despite the commonly cited advantages of off-site construction and the success of prefabricated construction around the world, the adoption of prefabricated construction in China is still at a low level. According to the "Deep research report on China prefabricated construction industry investment planning", the data show that in 2015, the proportion of prefabricated buildings in newly-built buildings accounted for only $2-3 \%$ in China [7]. Prefabricated building was first introduced to China in the 1960s [7]. However, it only starts growing since 2012, with the policy support to transform and upgrade the Chinese traditional construction industry, and the promotion of the construction industrialization strategy by the Chinese government.

A body of research efforts have been taken to identify the barriers that are hindering the development of prefabricated construction (e.g., [5,8,9]). Previous researches have indicated that the off-site supply chain management is still a main challenge to the prefabrication development [5]. A number of scholars have explored the supply chain management in the domain of prefabricated construction. Existing efforts mainly focus on four aspects, such as the organizational form [10], information integration and supply chain optimization [11-14], building components production and management decision support [15-19], and knowledge sharing [20], which have undoubtedly contributed to a better development of the prefabricated construction industry. However, existing research is only trying to identify the single obstacle factors hindering prefabrication construction development, which is far from enough to the integrated management and system thinking of the entire supply chain. Therefore, it is necessary to think about how to promote prefabricated construction from a whole-system point of view, which means implementing supply chain management to realize the integration and collaboration of the main members in the supply chain, resources, and information in the prefabricated construction industry.

This paper conducts a study on organizing prefabricated construction industry from the market equilibrium perspective in the prefabricated construction supply chain. After the process of 
investigation and survey into the prefabricated construction in China, it is discovered that establishing a precast component enterprise needs a tract of land, factory building, advanced production lines imported from abroad, and so forth, which requires huge amount of investment. However, the business operation of most precast component enterprises is not well run because of the uncertainty of the market demand and the lack of technology management experience. Combined with literature review and field investigation in the domain of prefabricated construction, this paper tries to answer the following research questions:

- For the large construction enterprises, should the structural components be precast through establishing self-owned factory (i.e., self-manufacturing) or supplied by upstream independent component manufacturers (i.e., outsourcing)?

- For the small and medium-sized enterprises (SMEs) in construction, how do they participate in the prefabricated construction industry, considering that they have no independent component production capacity?

- What impacts does the self-manufacturing or outsourcing decision have on the whole supply chain, the different enterprises, and the prefabricated construction industry?

In order to answer the aforementioned questions, this paper takes the prefabricated construction supply chain consisting of one upstream component manufacturing enterprise and two downstream construction contractors as the object of study and establishes a comprehensive game model integrating Cournot and Stackelberg model (Cournot-Stackelberg model) from the perspective of market equilibrium. The market equilibrium results under the decisions of component self-manufacturing or outsourcing are presented. And the paper further discusses its effects on the organizational structure of prefabricated construction through optimizing profits of upstream and downstream enterprises in the prefabricated construction supply chain.

The rest of the paper is organized as follows. Section 2 provides an overview of the related background. Section 3 presents the modeling assumptions and the research methodology, including the comprehensive game model and the numerical analysis. Section 4 discusses the results of comparative analysis of the game model and the numerical simulation. Section 5 suggests the managerial implications for promoting the development of prefabrication construction industry. Finally, Section 6 concludes the paper and suggests the future research directions.

\section{Background}

\subsection{Supply Chain Management in Prefabricated Construction}

The concept of supply chain management (SCM) first appeared in the early 1980s [21]. The definition of SCM can be explained from three aspects: a management philosophy; a set of activities to implement a management philosophy; and a set of management processes [22]. First, as a management philosophy, the supply chain is viewed as a whole, rather than a set of fragmented parts $[23,24]$, which lays the emphasis on synchronization and convergence of intrafirm and interfirm operational and strategic capabilities [24]. Second, to implement the SCM philosophy successfully, various activities are required, such as mutually sharing information among supply chain members [23,25], sharing risks and rewards [26], cooperation [27], integration of processes from sourcing to manufacturing, and distribution across the supply chain [23,27], and building and maintaining long-term relationships [24,27]. The aforementioned activities are a coordinated effort called SCM between the supply chain partners to dynamically respond to the needs of the end customer [28]. Third, SCM is regarded as a process of managing relationships, information, and materials flow across enterprise borders. SCM can deliver enhanced customer service and economic value through synchronized management of the flow of physical goods and associated information from sourcing to consumption [29].

The SCM theory is originated from the manufacturing industry field and have been widely applied to many other industries, for example, construction, mining, transportation and storage, 
property and business services, to improve efficiency and save costs [30]. Since the construction industry is highly fragmented with significant negative impacts, that is, low productivity, cost and time overruns, conflicts and disputes, and resulting claims and time-consuming litigations, SCM is believed as a potential way to resolve the problems [31]. Construction supply chain belongs to project-based construction management, which is different from the process-based production management in the manufacturing industry. Previous research efforts indicated that successful methods of SCM have been widely implemented in construction project management [32]. Compared with traditional construction management, which is only limited to the secondary-level supply chain between the raw material supplier and the contractors, the SCM method is more suitable in the prefabricated construction management domain. Industrialization is one of the critical characteristics of the prefabricated construction methods. Prefabricated construction has a more complicated supply chain structure, for example, the component design, prefabrication, and installation can constitute a third-level supply chain; the raw material supplier and the component production factories can constitute a supply chain; the supply of the construction units, materials, or the intermediate products and the assembly construction can also constitute a supply chain.

A body of existing research efforts have applied the supply chain concept to the prefabricated construction domain. For example, strategic alliance was proved to be the optimal governance structure in terms of the organizational form of prefabricated construction supply chain [10]. Another crucial aspect is how to realize the production plan, supply materials and components in a timely manner, and optimize the project schedule by means of supply chain information collaboration. Nenad et al. [11] attempted to address those issues relating to the integration of information flows in relation to material management throughout the construction industry supply-chain through theoretically modeling for information mapping. Abedi et al. [12] come up with Context-Aware Cloud Computing Building Information Modeling (CACCBIM) to deliver appropriate and up-to-date information so as to enhance collaboration and integration management of supply chain. Hu et al. [13] pointed out that the organization, delivery and analysis of effective information was the core of breaking industry bottlenecks and put forward a cloud platform for prefabricated concrete components supply chain information collaboration to improve productivity and reduce the cost of concrete components. Zeng et al. [14] established a digital lean prefabricated construction platform integrating virtual construction technology, the Internet of things technology, cloud service technology, remote monitoring technology, and high-end aided engineering equipment based on the building information modeling (BIM) model to bring project participants and core elements of the key links into a unified platform.

The decision support for building components production and management, and the supply chain collaboration management between production, transportation, and fabrication are an important research topic for organizing prefabrication construction industry. Kamar and Hamid [15] believed that the Industrialized Building System supply chain required close control of materials and resource management to ensure continuity and the timely delivery of construction components, and contractors needed to adopt partnering initiatives, information technology, and open collaborative environment to manage the supply chain. Ko [16] developed a plan involving a lead-time estimation model (LTEM) and schedule adjustment principles to continuously improve production control systems for precast fabrication. Ko and Wang [17,18] developed Genetic Algorithm-based Decision Support Systems (GA-DSS) to assist production managers in arranging production plans [17], and a multi-objective precast production scheduling model (MOPPSM) considering production sources and buffer size [18]. Anvari et al. [19] proposed a multi-objective Genetic Algorithm-based (GA-based) searching technique to solve resource planning problems in the process of production, transportation and fabrication of precast components. From the angle of knowledge sharing, Shan and Li [20] investigated knowledge sharing mechanism of industrialized building supply chain under the bounded rationality by analyzing the system evolution path and evolutionary stable strategy using the evolutionary game theory. 
In terms of the function of SCM, the literature indicates that the research tends to fall within four main streams, namely, distribution, production, strategic procurement, and industrial organizational economics [33]. Existing supply chain studies in the construction domain mainly focus on the technology and efficiency perspective to resolve various issues in construction projects, such as low productivity, cost overruns, time delays, quality defects, and conflicts and disputes among companies in the supply chains. For example, Yeo and Ning [34] proposed an enhanced framework for procurement management by coupling the SCM concepts and critical chain project management; Irizarry et al. [35] integrated Building Information Modeling (BIM) and Geographic Information Systems (GIS) into a unique system to visualize the supply chain process and the actual status of materials through the supply chain; Xue et al. [36] presented two types of internet-enabled coordination mechanisms, namely, market mechanism and coordination flow, as platforms for construction supply chain coordination to improve construction performance. However, there is a scarcity of literature on the industrial organizational economics of the construction supply chain management (CSCM) [37]. To the best of the authors' knowledge, there are no existing efforts on the organization mode of the prefabricated construction industry from a market equilibrium perspective. In order to address this gap, this paper proposed a market equilibrium supply chain model to study the industrial organization in the prefabricated construction.

\subsection{Cournot-Stackelberg Model}

Two main approaches have been used to model the construction supply chain, that is, agent-based modeling (ABM) and equation-based modeling (EBM) [38]. One of the main differences of the ABM and EBM approach is the level of focus. The ABM approach (e.g., [39-41]) explores the dynamic interactions among agents/entities in the supply chain, which focuses more on individual agents and how the interactions among the individual agents influence the system over time [42]. On the contrary, the EBM approach (e.g., [43]) models the supply chain from a system perspective. It formulates a set of equations to express relationships among the entities [38]. In this study, the EBM approach was selected to focus on the market structure (i.e., competition and monopoly) and the equilibrium state of the whole system. Specifically, this paper used theoretical economic models to explain the behaviors of different firms, and to study the prefabricated industrial organization mode.

Several economic models have been developed to describe/analyze the different types of competition and economic market. Such economic models commonly based on distinct assumptions, level of competitions, and decision variables. As this paper only focuses on the prefabrication market in China, the most related economic models are the Cournot Model, the Bertrand Model, and the Stackelberg Model, because the current prefabrication market structure in China is a typical oligopoly market, and the aforementioned three economic models are the classic oligopoly game models.

The main difference between the Cournot Model and the Bertrand Model is the decision variable. In the Cournot Model, the decision variable is product quantity, while in the Bertrand Model, the decision variable is product price [44]. This paper should select the Cournot Model, because as the market capacity of the current prefabricated construction in China is limited, the market clearing price to sell all the prefabricated construction products is a function of the product quantity.

The Cournot Model, also known as Cournot Duopoly Model or Duopoly Model, is an economic model that was first introduced by French mathematician Augustin Cournot in 1838. The Cournot Model analyzes the competition of two or more players/firms. It assumes that the firms in the oligopoly market produce homogeneous and undifferentiated products, and that they cannot collude. Each firm aims to maximize its expected profit by taking actions based on the reaction of its competitor, and they move simultaneously. The profit is maximized when marginal revenue equals the marginal cost [34].

The development of the construction market in China is highly unbalanced in the eastern, central, or western regions, which results in a regional development characteristic. Meanwhile, the prefabricated construction industry in China is still at an initial development stage. The majority of construction companies are still using traditional construction approaches. There is a scarcity of 
construction companies that are willing to enter the prefabrication market. Therefore, this study assumes that in one province or region, only one large construction company and one innovative SME contractor will enter the prefabricated construction market, which is in accordance with both the basic assumptions of the Cournot Model, and the current development conditions of China's prefabricated construction market.

The Stackelberg Model is an extension of the Cournot Model. The Stackelberg Model follows the same assumptions as the Cournot Model, except that the firms decide sequentially. In the Stackelberg Model, the leader firm has the "first mover advantage" to choose its move, then the follower firm chooses its move after observing the move chosen by the leader company to maximize its profit. This is a perfect information dynamic game [45]. In the supply chain constituted by the component production firms and the construction firms, a typical make-to-order (MTO) construction process is utilized, therefore, the information between the upstream and downstream companies is completely transparent, and forms the Stackelberg competition.

In this paper, the authors used the Cournot-Stackelberg Model, which nested the Cournot Model in the Stackelberg Model, to build a decision model for a supply chain between one upstream component manufacturing company and two competing downstream contractors, to identify the influence of the contractor's self-manufacturing or outsourcing decisions to the profit of the supply chain companies and the whole supply chain, and to analyze the organizational form of the prefabricated construction industry from a market equilibrium perspective.

\section{Research Methodology}

The research methodology includes two main steps: (1) game-theoretic analysis, and (2) numerical simulation. The game-theoretic analysis aims to establish the Cournot-Stackelberg model and solve the equilibrium solutions of the output, price, and profit, under the component self-manufacturing or outsourcing decision scenarios. The numerical simulation aims to present the examples of the model implementation, and analyze the profit changes of the whole supply chain and the main supply chain members under different decisions by changing the market size.

\subsection{Game-Theoretic Analysis}

\subsubsection{Assumptions}

Consider a supply chain consisting of one upstream component manufacturing company $\mathrm{S}$ and two downstream contractors, A and B. Contractor A is a large construction enterprise, which is enormously powerful and able to lead the industry innovation. And Contractor B is a SME construction enterprise, which shows a keen interest in new technologies and developing modes such as prefabricated construction, building information modeling (BIM), and so forth, and hopes to take advantage of this opportunity to speed up its development. Contractor A must make decisions whether to set up a component factory to produce the construction components by itself (self-manufacturing) or to purchase the construction components from the component suppliers (outsourcing), while Contractor B can only get precast components through the supply of component factories. The component production line has to be introduced from developed countries, which requires huge investments and highly complex technologies. Therefore, the component production enterprises tend to have strong market power, with a certain monopoly and corresponding pricing power in the component production market.

This article assumes that one construction unit (beam, column, slab, wall, etc.) can produce one unit of prefabricated building product. As well, the cost to produce one unit of prefabricated building product by Contractor $\mathrm{A}$ is smaller than that by Contractor $\mathrm{B}$. The market demand function that the contractors face with is $p=a-q_{A}-q_{B}$, where $a$ is the market size (constant) and $p$ is the market equilibrium price of prefabricated building products. 
If Contractor A decides to manufacture precast components by establishing its own factory, Contractor $\mathrm{B}$ and the component manufacturing enterprise will form a supply chain, and will compete with Contractor A. This scenario will lead to the squeezing of the component market demand from the component supplier, and promote the vertical internal integration of the supply chain. If Contractor $\mathrm{A}$ chooses the outsourcing decision, Contractor A, B and the component supplier will form a composite industrial organization. Contractor A will compete with Contractor B in the same component market. This scenario is beneficial to promote scale development of the component factory, and enlarge scale economic effects. Hence, the decision-making behavior of the large contractors directly influences the market structure and competitive relationship of the prefabricated construction industry. It is static Cournot competition of complete information between Contractor A and B, and dynamic Stackelberg competition between upstream component supplier and downstream contractors. A list of the notations used in this paper is summarized in Table A1.

\subsubsection{Component Self-Manufacturing Decision}

If Contractor A makes the component self-manufacturing decision, Contractor B will be the only client of the upstream component factory $\mathrm{S}$. Therefore, Contractor B and $\mathrm{S}$ form a supply chain. The profit functions of S, Contractor A and B can be expressed as Equations (1)-(3), respectively.

$$
\begin{gathered}
\pi_{s}^{z}=\left(P_{z}-C_{s}\right) q_{B} \\
\pi_{A}^{z}=\left(p-C_{A}-C_{Z}\right) q_{A}=\left(a-q_{A}-q_{B}-C_{A}-C_{Z}\right) q_{A} \\
\pi_{B}^{z}=\left(p-C_{B}-P_{Z}\right) q_{B}=\left(a-q_{A}-q_{B}-C_{B}-P_{Z}\right) q_{B}
\end{gathered}
$$

where $\pi_{S}^{z}, \pi_{A}^{z}$, and $\pi_{B}^{z}$ denote the profit of the component factory S, Contractor A, and Contractor $B$ under self-manufacturing decision, respectively; $q_{A}$ and $q_{B}$ denote the production quantity of Contractor $A$ and $B$, respectively; $C_{A}$ and $C_{B}$ are assembly costs of Contractor $A$ and $B$ producing one unit of prefabricated building, respectively, and $C_{A}<C_{B} ; P_{z}$ is the unit purchase price of Contractor $\mathrm{B}$; $C_{S}$ is the unit production cost of Component Supplier $S$; and $C_{Z}$ is the unit self-manufacturing cost of Contractor A.

To find the optimal production quantity $q_{A}$ and $q_{B}$ (i.e., the equilibrium quantity for Contractor A and B), take the first derivative of $\pi_{A}^{z}$ with respect to $q_{A}$ and set to zero. It can be shown that $\frac{\partial \pi_{A}^{z}}{\partial q_{A}}=-2 q_{A}+a-q_{B}-C_{A}-C_{Z}=0$.

The optimal production quantity of Contractor A can therefore be determined as Equation (4).

$$
q_{A}=\frac{a-q_{B}-C_{A}-C_{Z}}{2}
$$

Similarly, put the first derivative of $\pi_{B}^{z}$ with respect to equal to $q_{B}$ equal to zero, and get

$$
q_{B}=\frac{a-q_{A}-C_{B}-P_{Z}}{2}
$$

Combine Equations (4) and (5) to form a linear system for variables $q_{A}$ and $q_{B}$, and find the solution for the linear system as Equations (6) and (7)

$$
\begin{aligned}
q_{A} & =\frac{a+C_{B}+P_{Z}-2 C_{A}-2 C_{Z}}{3} \\
q_{B} & =\frac{a+C_{A}+C_{z}-2 C_{B}-2 P_{Z}}{3}
\end{aligned}
$$


According to the values of $q_{A}$ and $q_{B}$, further calculate the component supply price $P_{z}^{*}$ to maximize the profit of the component supplier, obtaining

$$
P_{z}^{*}=\frac{a+C_{A}+2 C_{s}+C_{z}-2 C_{B}}{4}
$$

Bring Equation (8) into Equations (4) and (5), obtaining the equilibrium output $q_{A}^{z *}$ and $q_{B}^{z *}$,

$$
\begin{gathered}
q_{A}^{z *}=\frac{5 a-7 C_{A}+2 C_{B}+2 C_{s}-7 C_{Z}}{12} \\
q_{B}^{z *}=\frac{a+C_{A}-2 C_{B}+C_{z}-2 C_{s}}{6}
\end{gathered}
$$

The profits of component supplier S $\left(\pi_{S}^{z *}\right)$, Contractor A $\left(\pi_{A}^{z *}\right)$ and $\mathrm{B}\left(\pi_{B}^{z *}\right)$, and the market equilibrium price $\left(p^{z *}\right)$ are thus calculated:

$$
\begin{aligned}
\pi_{s}^{z *} & =\frac{\left(a+C_{A}-2 C_{B}+C_{z}-2 C_{s}\right)^{2}}{24} \\
\pi_{A}^{z *} & =\frac{\left(5 a-7 C_{A}+2 C_{B}-7 C_{z}+2 C_{s}\right)^{2}}{144} \\
\pi_{B}^{z *} & =\frac{\left(a+C_{A}-2 C_{B}+C_{z}-2 C_{s}\right)^{2}}{36} \\
p^{z *} & =\frac{5 a+5 C_{A}+2 C_{B}+5 C_{z}+2 C_{s}}{12}
\end{aligned}
$$

\subsubsection{Component Outsourcing Decision}

If Contractor A makes the component outsourcing decision, the upstream component supplier $\mathrm{S}$ will become the supplier of both Contractor $\mathrm{A}$ and $\mathrm{B}$. The upstream component supplier will give a discount of purchase price according to the demand: $P_{i}^{w}=\theta+\frac{\eta}{q_{i}},(i=A, B)$, where $\theta$ is decision variable, $\eta$ is a parameter, and $q_{i}$ is the production quantity of prefabricated building for Contractor $i$. The profit functions of S, Contractor A and B can be expressed as Equations (15)-(17), respectively.

$$
\begin{aligned}
& \pi_{s}^{w}=P_{A}^{w} q_{A}+P_{B}^{w} q_{B}-\left(q_{A}+q_{B}\right) C_{s} \\
& \pi_{A}^{w}=\left(a-q_{A}-q_{B}-C_{A}-P_{A}^{w}\right) q_{A} \\
& \pi_{B}^{w}=\left(a-q_{A}-q_{B}-C_{B}-P_{B}^{w}\right) q_{B}
\end{aligned}
$$

where $\pi_{s}^{w}, \pi_{A}^{w}$, and $\pi_{B}^{w}$ denote the profit of the component factory S, Contractor $\mathrm{A}$, and Contractor $\mathrm{B}$ under outsourcing decision, respectively.

Bring $P_{i}^{w}=\theta+\frac{\eta}{q_{i}}(i=A, B)$ into Equations (16) and (17), then respectively take the first derivative with respect to $q_{A}$ and $q_{B}$, obtaining

$$
\begin{aligned}
q_{A} & =\frac{a-q_{B}-C_{A}-\theta}{2} \\
q_{B} & =\frac{a-q_{A}-C_{B}-\theta}{2}
\end{aligned}
$$

Combine Formulas (18) and (19) through a simultaneous solution, obtaining the equilibrium output of the Contractor A $\left(q_{A}^{w *}\right)$ and B $\left(q_{B}^{w *}\right)$,

$$
q_{A}^{w *}=\frac{a-2 C_{A}+C_{B}-\theta}{3}
$$




$$
q_{B}^{w *}=\frac{a+C_{A}-2 C_{B}-\theta}{6}
$$

Bring Formulas (19) and (20) into Formula (15), and take the first derivative with respect to $\theta$, obtaining

$$
\theta=\frac{2 a-C_{A}-C_{B}+2 C_{s}}{4}
$$

In accordance with the value of $\theta$, obtain the equilibrium output $q_{A}^{w *}$ and $q_{B}^{w *}$ for Contractor $\mathrm{A}$ and $\mathrm{B}$, market equilibrium price $p^{w *}$, purchase price $P_{A}^{w *}$ and $P_{B}^{w *}$ for Contractor $\mathrm{A}$ and $\mathrm{B}$, and equilibrium profit $\pi_{S}^{w *}, \pi_{A}^{w *}$, and $\pi_{B}^{w *}$ for component supplier $\mathrm{S}$, Contractor $\mathrm{A}$, and Contractor $\mathrm{B}$ under the outsourcing decision, respectively,

$$
\begin{gathered}
q_{A}^{w *}=\frac{2 a-7 C_{A}+5 C_{B}-2 C_{s}}{12} \\
q_{B}^{w *}=\frac{2 a+5 C_{A}-7 C_{B}-2 C_{s}}{12} \\
p^{w *}=\frac{4 a+C_{A}+C_{B}+2 C_{s}}{6} \\
P_{A}^{w *}=\frac{2 a-C_{A}-C_{B}+2 C_{s}}{4}+\frac{12 \eta}{2 a-7 C_{A}+5 C_{B}-2 C_{s}} \\
P_{B}^{w * *}=\frac{2 a-C_{A}-C_{B}+2 C_{s}}{4}+\frac{12 \eta}{2 a+5 C_{A}-7 C_{B}-2 C_{s}} \\
\pi_{S}^{w *}=\frac{\left(2 a-C_{A}-C_{B}-2 C_{s}\right)^{2}}{24}+2 \eta \\
\pi_{A}^{w *}=\frac{\left(2 a-7 C_{A}+5 C_{B}-2 C_{S}\right)^{2}}{144}-\eta \\
\pi_{B}^{w *}=\frac{\left(2 a+5 C_{A}-7 C_{B}-2 C_{S}\right)^{2}}{144}-\eta
\end{gathered}
$$

The market equilibrium price, output, and profit of the upstream Component Supplier S, Contractor A, and Contractor B, when Contractor A takes the self-manufacturing or outsourcing decisions are summarized in Table 1.

Table 1. Summary of market equilibrium price, output, and profit.

\begin{tabular}{cccc}
\hline \multicolumn{2}{c}{ Decisions of Contractor A } & Self-Manufacturing & Outsourcing \\
\hline \multicolumn{2}{c}{ Market equilibrium price } & $\frac{5 a+5 C_{A}+2 C_{B}+5 C_{z}+2 C_{s}}{12}$ & $\frac{4 a+C_{A}+C_{B}+2 C_{s}}{6}$ \\
\hline \multirow{3}{*}{ Equilibrium output } & Contractor A & $\frac{5 a-7 C_{A}+2 C_{B}+2 C_{s}-7 C_{Z}}{12}$ & $\frac{2 a-7 C_{A}+5 C_{B}-2 C_{s}}{12}$ \\
& Contractor B & $\frac{a+C_{A}-2 C_{B}-2 C_{S}}{6}$ & $\frac{2 a+5 C_{A}-7 C_{B}-2 C_{s}}{12}$ \\
\hline \multirow{3}{*}{ Profit } & Upstream Component & $\frac{\left(a+C_{A}-2 C_{B}+C_{z}-2 C_{s}\right)^{2}}{24}$ & $\frac{\left(2 a-C_{A}-C_{B}-2 C_{s}\right)^{2}}{24}+2 \eta$ \\
& Supplier S & $\frac{\left(5 a-7 C_{A}+2 C_{B}-7 C_{z}+2 C_{s}\right)^{2}}{144}$ & $\frac{\left(2 a-7 C_{A}+5 C_{B}-2 C_{s}\right)^{2}}{144}-\eta$ \\
& Contractor A & $\frac{\left(a+C_{A}-2 C_{z}-2 C_{s}\right)^{2}}{36}$ & $\frac{\left(2 a+5 C_{A}-7 C_{B}-2 C_{s}\right)^{2}}{144}-\eta$ \\
\hline
\end{tabular}

\subsection{Numerical Simulation}

Under the background that the prefabricated construction market in China is still in the initial growth stage, this study assumed that the assembly cost of Contractor A is less than that of Contractor $\mathrm{B}$, while the component self-manufacturing cost of Contractor A is slightly higher than the production cost of Component Supplier S. Therefore, for the sake of calculation simplicity, the related parameters were assumed by the authors as follows: $C_{A}=60 ; C_{B}=80 ; C_{s}=18 ; C_{z}=20 ; \eta=90$. A set of different market sizes were assumed to represent the growth trend of the prefabricated construction 
market, and to observe the influence of self-manufacturing or outsourcing decisions on the industrial organization and market structure. The profits of the Component Supplier S, Contractor A and B, under the precast component self-manufacturing or outsourcing decisions of Contractor $\mathrm{A}$, are then calculated based on the equations in Table 1.

\section{Results and Discussions}

\subsection{Comparative Analysis under Self-Manufacturing and Outsourcing Decisions}

The comparative analysis is based on the results from the game-theoretic analysis (i.e., Table 1). In terms of profits, if the profit of Contractor A under self-manufacturing decision is greater than that under outsourcing decision, that is, $\frac{\left(5 a-7 C_{A}+2 C_{B}-7 C_{z}+2 C_{S}\right)^{2}}{144}-\left(\frac{\left(2 a-7 C_{A}+5 C_{B}-2 C_{s}\right)^{2}}{144}-\eta\right) \geq 0$, Contractor A should take the component self-manufacturing strategy. In this case, $\eta$ is smaller than $-\frac{7\left(a-2 C_{A}+C_{B}-C_{S}\right)\left(3 a-7 C_{z}-3 C_{B}+4 C_{S}\right)}{144}$. Otherwise, it is appropriate to take the component outsourcing strategy.

When Contractor A takes the component self-manufacturing strategy, the profit that Contractor B can get is $\frac{\left(a+C_{A}-2 C_{B}+C_{z}-2 C_{S}\right)^{2}}{36}$, which is guaranteed to be non-negative, and is not correlated with the parameter $\eta$. Contractor $B$ can, thus, achieve a higher profit by strengthening its price negotiation with the component supplier, or reducing its own assembly costs.

When Contractor A takes the component outsourcing strategy, the highest profit that Contractor $B$ can get is $\frac{\left(2 a+5 C_{A}-7 C_{B}-2 C_{s}\right)^{2}+7\left(a-2 C_{A}+C_{B}-C_{s}\right)\left(3 a-7 C_{z}-3 C_{B}+4 C_{s}\right)}{144}$, which is possible to be negative. Therefore, when the profit is negative, Contractor $\mathrm{B}$ will not join the prefabricated construction market.

From the angle of the industrial organization, the difference of the equilibrium output for Contractor B under the outsourcing or self-manufacturing decisions of Contractor A can be expressed as $q_{B}^{w *}-q_{B}^{z *}=\frac{3\left(C_{A}-C_{B}\right)+2\left(C_{S}-C_{z}\right)}{12}$. According to the assumption in Section 3.1.1, $C_{A}$ is smaller than $C_{B}$. If $C_{s}$ is smaller than $C_{z}$, that is, the self-manufacturing cost is higher than the cost of the upstream component manufacturing, then $q_{B}^{w *}$ is smaller than $q_{B}^{z *}$, which indicates that the decision on component outsourcing by Contractor A reduces the equilibrium output of Contractor B. At the same time, when Contractor A chooses component outsourcing, the equilibrium outputs of Contractor $A$ and $B$ are $\frac{2 a-7 C_{A}+5 C_{B}-2 C_{S}}{12}$ and $\frac{2 a+5 C_{A}-7 C_{B}-2 C_{S}}{12}$, respectively. In this case, the equilibrium outputs of Contractor $\mathrm{A}$ and $\mathrm{B}$ can only be influenced by the production cost of the two contractors and the component supplier. However, the price strategy adopted by the component supplier has no impact on the equilibrium outputs.

\subsection{Results and Discussions for Numerical Simulation}

The numerical simulation results are shown in Table 2, and further illustrated in Figures 1-4, where the $x$-axis represents the prefabricated construction market size, and the $y$-axis represents the profit.

Table 2. Profit changes of the supply chain and its main members in different market sizes under the two decisions on precast component self-manufacturing or outsourcing.

\begin{tabular}{ccccccccc}
\hline \multirow{2}{*}{$\begin{array}{c}\text { Market } \\
\text { Size }\end{array}$} & \multicolumn{3}{c}{ Profit When Self-Manufacturing } & \multicolumn{4}{c}{ Profit When Outsourcing } \\
\cline { 2 - 8 } & $\begin{array}{c}\text { Component } \\
\text { Supplier S }\end{array}$ & $\begin{array}{c}\text { Contractor } \\
\text { A }\end{array}$ & $\begin{array}{c}\text { Contractor } \\
\text { B }\end{array}$ & $\begin{array}{c}\text { Supply } \\
\text { Chain }\end{array}$ & $\begin{array}{c}\text { Component } \\
\text { Supplier S }\end{array}$ & $\begin{array}{c}\text { Contractor } \\
\text { A }\end{array}$ & $\begin{array}{c}\text { Contractor } \\
\text { B }\end{array}$ & $\begin{array}{c}\text { Supply } \\
\text { Chain }\end{array}$ \\
\hline 160 & 81 & 1320 & 54 & 1455 & 1044 & 394 & -86 \\
180 & 171 & 1995 & 114 & 2280 & 1591 & 560 & -61 \\
200 & 294 & 2809 & 196 & 3373 & 2271 & 732 & -15 \\
220 & 451 & 3762 & 300 & 4513 & 3084 & 934 & 54 & 4090 \\
240 & 641 & 4853 & 427 & 5921 & 4031 & 1158 & 145 \\
260 & 864 & 6084 & 576 & 7524 & 5111 & 1405 & 258 & 673 \\
280 & 1121 & 7453 & 747 & 9321 & 6324 & 1674 & 394 \\
\hline
\end{tabular}


Figure 1 shows the profit changes of Component Supplier S. The Component Supplier S can get more profits when Contractor A decides on component outsourcing, and the growth of profits is accelerating with the increase of the market size. However, this is a simplified model considering only one component manufacturing company. In fact, the specialization of labor will bring intense competitions among the component manufacturing companies, resulting in a certain sink effect on the high profit level of the component suppliers. But the overall profit level should still tend to rise.

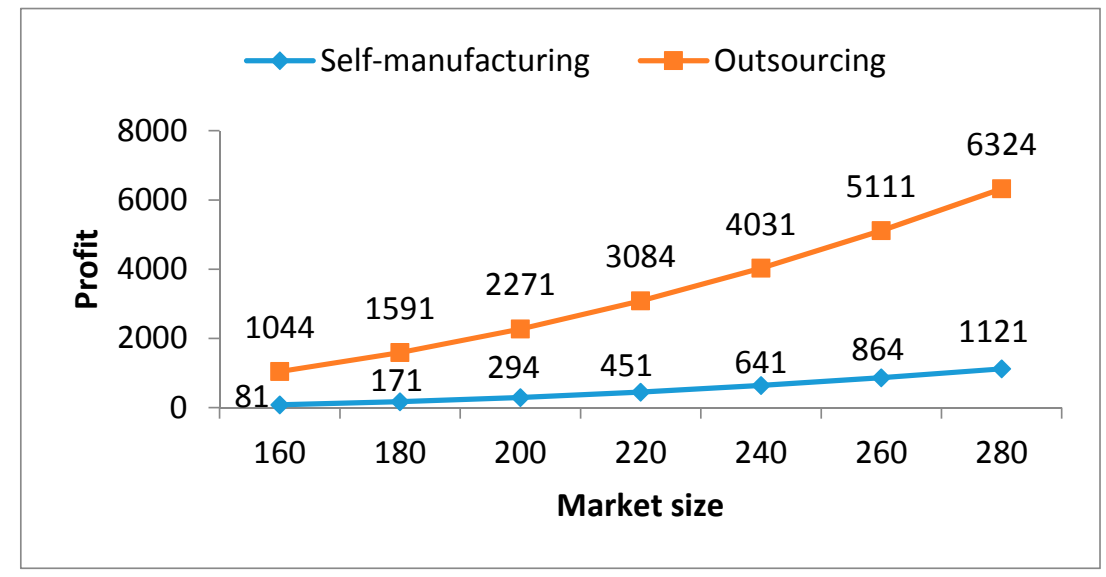

Figure 1. Profit changes of the component supplier in different market sizes under the two decisions on precast component self-manufacturing or outsourcing.

Figure 2 shows the profit changes of Contractor A. The changes of the profit level for Contractor A has a similar tendency with Component Supplier S. But a higher profit level happens when Contractor A decides on component self-manufacturing. Two possible reasons are identified. On the one hand, at the initial stage of the prefabrication construction, the market competition is imperfect and there is a dearth of independently operated component manufacturing companies. As a result, the component manufacturing companies have a greater pricing power. On the other hand, the huge investment and operating costs of the component manufacturing factories may lead to a higher component price accordingly.

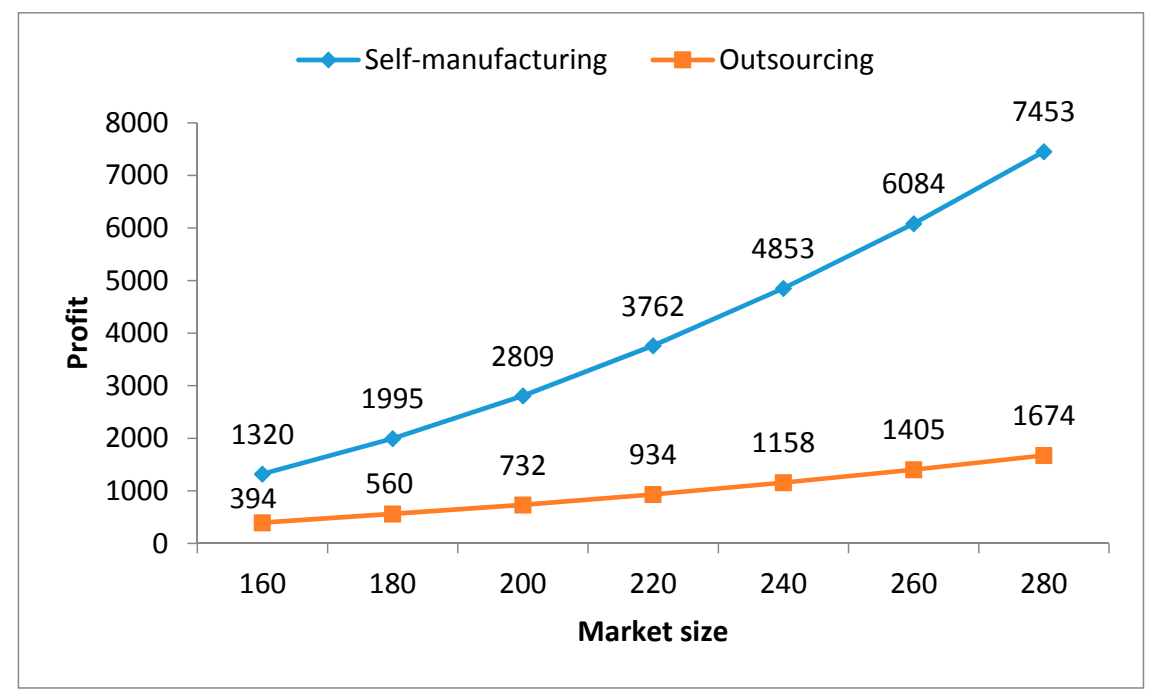

Figure 2. Profit changes of Contractor A in different market sizes under the two decisions on precast component self-manufacturing or outsourcing. 
Figure 3 shows the profit changes of Contractor B. The changes of the profit level for Contractor $\mathrm{B}$ are increasing synchronously under the component self-manufacturing or outsourcing decisions. However, the profit gap between the two decisions is not as large as that of Contractor A. One possible reason is that Contractor B can only develop through the component outsourcing, which results in a considerable amount of profit transferred to the upstream component supplier. Another reason could be the inferior position of Contractor B in the Stackelberg competition with Contractor A, because the output of the Contractor $\mathrm{B}$ depends on the selection of the production of Contractor A. In addition, because Contractor B has only one choice on needed components (i.e., component outsourcing), its profit level is more sensitive to the change of the market size. For example, in this numerical simulation, the critical value of the market size for Contractor B is 205. When the market size is smaller than 205, Contractor B will have negative profits and it may not engage in the prefabricated construction competition. Therefore, SME construction companies are faced with greater risks at the early developing stage in the prefabricated construction market.

Figure 4 shows the profit changes of the entire supply chain. Overall, with the increase of the market size, the profit level of the whole prefabricated construction supply chain and its main members tends to increase. The component self-manufacturing or outsourcing decisions by the large construction company have little influence on the profit level of the whole prefabricated construction supply chain. However, the industrial organization structure is transformed through the change of the profit distribution among the supply chain enterprises. We can see through Figures 1-4 that almost all the profits generated by the increased market size and the reduced profits by the component outsourcing decision by Contractor A are transferred to the component manufacturer.

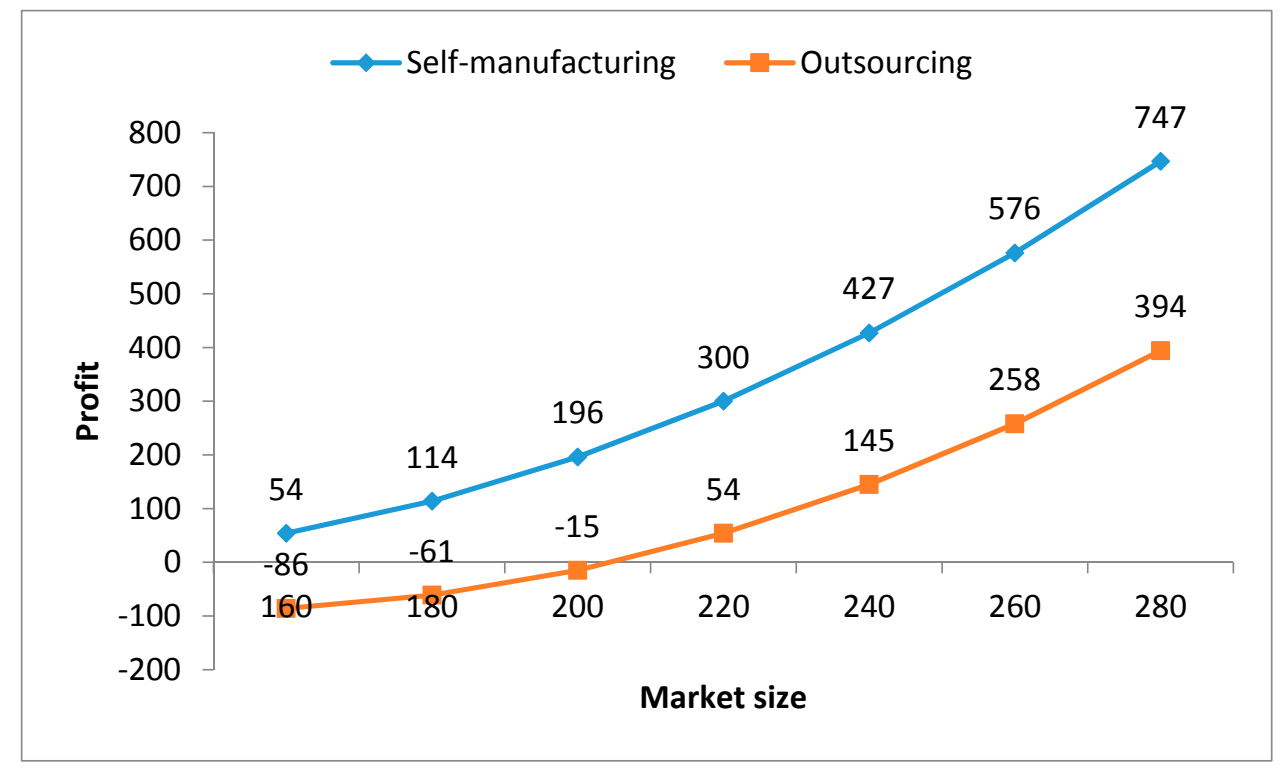

Figure 3. Profit changes of Contractor B in different market sizes under the two decisions on precast component self-manufacturing or outsourcing. 


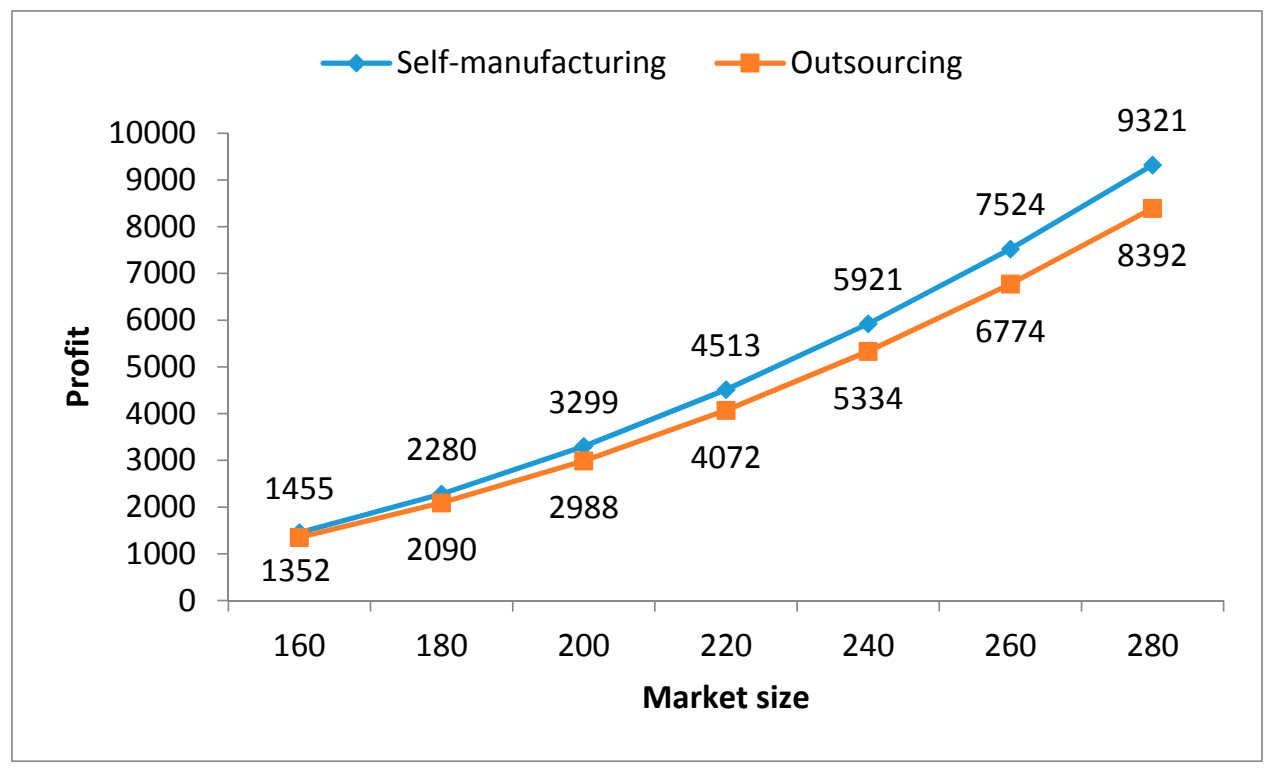

Figure 4. Profit changes of the whole supply chain in different market sizes under the two decisions on precast component self-manufacturing or outsourcing.

\section{Managerial Implications}

The research results indicate that the SME contractors are more sensitive to the market size changes in the prefabricated construction industry than the large ones. If the market size is smaller than a certain critical value, for example, 205 in the previous numerical simulation, the SME construction enterprises tend to have a high risk to lose compared to large ones. In the process of cultivating prefabricated building industry, the government should not only enact relevant policies to support large enterprises, but also pay more attention to enlarging the prefabricated construction market scale to ensure that the SME construction enterprises have enough profits to inspire their initiative and creativity, thereby advancing the prefabricated construction market in a collaborative way. We can also conclude that the market demand on prefabricated building is a fundamental motive force to the development of the prefabricated construction industry. More effective policy measures should be launched to accelerate the cultivation and growth of the main market players in the prefabricated construction industry, to facilitate the social division and cooperation and to strengthen the industrial chain integration.

The component manufacturing enterprise is the biggest beneficiary of self-development, which has created abundant opportunities, laid the foundation for implementing supply chain management, made sufficient use of specialization of labor, and established industrial alliance. However, in the current prefabricated construction supply chain, the component manufacturing company is the weakest market player because of varieties of constraints, such as lack of professional technician and management personnel, large early investment for the automated production line, and insufficient production and management experience. Hence, the company scale and the growth speed of the component manufacturing enterprises should adapt to the development stage and requirements of the prefabricated construction industry, rather than expanding the production capacity blindly.

Significant challenges still exist in shifting from "traditional and on-site construction" to "innovative and industrialized housing" [46]. More actions and government supports are, thus, needed to increase the take up of prefabrication and better support the development of the prefabricated construction industry.

First, more government policies in favor of the prefabricated construction are needed. On the one hand, the promotion of the prefabricated construction is needed to meet the construction market demand. A large number of public housing are invested and constructed every year by Chinese 
central and local governments in order to satisfy the housing needs of low-income families. Mandatory policies can, therefore, be issued to take the prefabricated construction method in public buildings, government buildings, and affordable housings, in order to ensure a certain market scale. On the other hand, prefabricated construction can improve the circular economy. The standardized and industrialized production of the building components can reduce the waste of building materials, water, and land, and improve the recycling of resources. The mechanized assembly construction can greatly reduce labor demand, accelerate construction progress, reduce wet operations, and thereby achieve ecological construction.

Second, it is necessary to strengthen the guidance for the component manufacturing enterprises with respect to the technological innovation, operation, management, and investment, and promote the prefabricated construction in a collaborative way. The prefabrication process is highly complex. The structure and function of different prefabricated components are heterogeneous. Therefore, the coordination and collaboration is especially important in the whole prefabricated construction process. On the one hand, not only should the hardware equipment be introduced from the developed countries and regions, but advanced experience of technology and management should also be used for reference by component manufacturers. It is crucial to establish guidelines and clarify the investment requirements for the precast component factories by combining with the current development status and in accommodate with the development scale of the prefabricated construction industry in China. On the other hand, component standardization and building information modeling (BIM) technology are effective methods to achieve synergies of architecture design, production, and construction. For example, component standardization can be a carrier to connect the different links in the prefabricated construction supply chain, thereby improve the collaboration from a technical level. BIM technology can improve the information sharing and transmission among different subjects and processes, effectively solve the problems such as geographical restrictions, standard differences, and communication barriers, and promote the coordination of the whole prefabricated construction process.

Third, the integration of industrial chains needs strengthened for the mutual development of the whole prefabricated industry. From a broad perspective, the prefabricated industrial chain includes market analysis, land resources development, project design, material supply, component production and transportation, component integration and assembly, commodity circulation, and property management. For a specific process, there also exist many embedded dynamic chains. For example, in the component production process, the embedded chain includes the product design, staff training, material supply, component production, product design amendment, product testing, and component parts transportation. Therefore, building an integrated industrial chain among the product design, production, and construction enterprises, can improve the mutual complementation of technology, resources, and information, and achieve risk sharing.

Fourth, more education and motivation is required to enhance the public understanding and cognition of the benefits of the prefabricated construction. The successful shift from the traditional construction methods, which has been utilized for centuries, also involves a shift in culture and public attitudes [2]. More propagation, for example, using multimedia such as newspapers, televisions, and radios, and in various forms, such as press conferences, expos, and advertising videos, will inform the public of the advantages of prefabricated construction, such as higher construction quality, improved safety, better living environment, and so forth, and thereby stimulate the potential market demand on prefabricated buildings.

\section{Conclusions and Future Research Directions}

This study considers a prefabricated construction supply chain, which is composed of one upstream component manufacturer and two downstream contractors. The large contractor can get precast components through self-manufacturing or outsourcing, while the SME contractor can only buy components from the component manufacturer. A comprehensive game model (Cournot-Stackelberg 
model) is established under two decision scenarios, that is, component self-manufacturing or outsourcing. The equilibrium solutions of the output, price and profit are calculated by solving the profit functions in the prefabricated construction supply chain, which indicate the optimal decision on production, operation, and the profit's boundary conditions.

The profit levels are analyzed based on dynamic simulations by changing the market sizes of prefabricated construction under different decisions. The results of this study shows that: (1) the profit levels of the entire supply chain and all the enterprises in it are increasing with the increase of the market size; (2) the downstream contractors have a higher profit level under the component self-manufacturing decision than under the component outsourcing decision, but on the contrary, the upstream component suppliers get a higher profit level under the component outsourcing decision; and (3) the SME contractor is in a disadvantageous position in the market competition; the equilibrium output of the SME contractor is reduced under the outsourcing decision of the large contractor, and it is faced with high risks when the market size is small; however, a higher profit level can be expected with the increase of the market size. According to the previous analysis, managerial implications are put forward from the angles of extensive publicity, mandatory implementation, strengthening industrial chain integration, and intensifying component factory guidance, in order to promote the development of the prefabricated construction.

This paper mainly discussed the short-term supply chain equilibrium problem of the prefabricated construction market at the initial stage. The main characteristics of this stage include the small number of large companies dominating the market, incomplete market infrastructure, and lack of supporting industries. With the increase of the market demand and the expansion of the market size, more and more enterprises at different parts of the supply chain will participate in the prefabricated construction, which can fundamentally change the industrial structure and organizational mode. Therefore, it is necessary to establish a more practical model according to the real situation of the prefabricated construction market. In addition, the component self-manufacturing or outsourcing decisions will result in different transaction costs for the large contractor, which will be further explored in the future.

Acknowledgments: This research is jointly supported by the National Natural Science Foundation of China (Grant No. 71301013), Xi'an Urban and Rural Construction Commission (Grant No. SJW2016-04), and the Fundamental Research Funds for the Central Universities (Grant No. 310828161003, 310823170429). Their support is gratefully acknowledged. The authors would like to thank the editors, reviewers and experts for their time and constructive comments.

Author Contributions: All three authors were involved in conceiving the goals, objectives, and structure of the paper. Yanhu Han designed and performed the research. Yanhu Han and Lufan Wang both wrote the paper, and reviewed and edited the manuscript drafts. Miroslaw J. Skibniewski provided valuable insights and constructive comments on the paper writing and submission. All authors have therefore been involved in the preparation and have approved the final manuscript.

Conflicts of Interest: The authors declare no conflict of interest.

\section{Appendix A}

Table A1. Summary of Notations.

\begin{tabular}{clcl}
\hline Notation & \multicolumn{1}{c}{ Meaning } & Notation & \multicolumn{1}{c}{ Meaning } \\
\hline$\pi_{s}^{z}$ & $\begin{array}{l}\text { Profit of Component Supplier S } \\
\text { under self-manufacturing decision }\end{array}$ & $\pi_{s}^{w}$ & $\begin{array}{l}\text { Profit of Component Supplier S under } \\
\text { outsourcing decision }\end{array}$ \\
\hline$\pi_{A}^{z}$ & $\begin{array}{l}\text { Profit of Contractor A under } \\
\text { self-manufacturing decision }\end{array}$ & $\pi_{A}^{w}$ & $\begin{array}{l}\text { Profit of Contractor A under } \\
\text { outsourcing decision }\end{array}$ \\
\hline$\pi_{B}^{z}$ & $\begin{array}{l}\text { Profit of Contractor B under } \\
\text { self-manufacturing decision }\end{array}$ & $\pi_{B}^{w}$ & $\begin{array}{l}\text { Profit of Contractor B under } \\
\text { outsourcing decision }\end{array}$ \\
\hline$q_{A}$ & Production quantity of Contractor A & $a$ & Market size \\
\hline$q_{B}$ & Production quantity of Contractor B & $p$ & $\begin{array}{l}\text { Market equilibrium price, } \\
p=a-q_{A}-q_{B}\end{array}$ \\
\hline
\end{tabular}


Table A1. Cont.

\begin{tabular}{clll}
\hline Notation & \multicolumn{1}{c}{ Meaning } & Notation & \multicolumn{1}{c}{ Meaning } \\
\hline$C_{A}$ & Assembly cost of Contractor A & $C_{S}$ & $\begin{array}{l}\text { Unit production cost of Component } \\
\text { Supplier S }\end{array}$ \\
\hline$C_{B}$ & Assembly cost of Contractor B & $C_{Z}$ & $\begin{array}{l}\text { Unit self-manufacturing cost of } \\
\text { Contractor A }\end{array}$ \\
\hline$P_{z}$ & $\begin{array}{l}\text { Unit purchase price of Contractor B } \\
\text { under self-manufacturing decision }\end{array}$ & $P_{i}^{w}$ & $\begin{array}{l}\text { Unit purchase price of Contractor A and } \\
\text { B under outsourcing decision, } i=A, B\end{array}$ \\
\hline
\end{tabular}

\section{References}

1. Chen, Y.; Okudan, G.E.; Riley, D.R. Decision support for construction method selection in concrete buildings: Prefabrication adoption and optimization. Autom. Constr. 2010, 19, 665-675. [CrossRef]

2. Arif, M.; Egbu, C. Making a case for offsite construction in China. Eng. Constr. Archit. Manag. 2010, 17, 536-548. [CrossRef]

3. Aye, L.; Ngo, T.; Crawford, R.H.; Gammampila, R.; Mendis, P. Life cycle greenhouse gas emissions and energy analysis of prefabricated reusable building modules. Energy Build. 2012, 47, 159-168. [CrossRef]

4. Mao, C.; Shen, Q.; Shen, L.; Tang, L. Comparative study of greenhouse gas emissions between off-site prefabrication and conventional construction methods: Two case studies of residential projects. Energy Build. 2013, 66, 165-176. [CrossRef]

5. Xu, X.; Zhao, Y. Some Economic Facts of the Prefabricated Housing; Industry Report; Rutgers Business School: Newark, NJ, USA, 2010.

6. Jaillon, L.; Poon, C.S. The evolution of prefabricated residential building systems in Hong Kong: A review of the public and the private sector. Autom. Constr. 2009, 18, 239-248. [CrossRef]

7. Polat, G. Precast concrete systems in developing vs. industrialized countries. J. Civ. Eng. Manag. 2010, 16, 85-94. [CrossRef]

8. Goodier, C.I.; Gibb, A.G.F. Barriers and Opportunities for Offsite in the UK. In Systematic Innovation in the Management of Project and Processes, Proceedings of the 11th Joint CIB International Symposium Combining Forces-Advancing Facilities Management and Construction through Innovation, Helsinki, Finland, 13-16 June 2005; Abdul, S.K., Ed.; Loughborough University: Leicestershire, UK, 2005; pp. 148-158.

9. Kamar, K.A.M.; Alshawi, M.; Hamid, Z.A. Barriers To Industrialized Building System (IBS): The Case of Malaysia. In Proceedings of the BuHu 9th International Postgraduate Research Conference (IPGRC), Salford, UK, 29-30 January 2009; pp. 1-16.

10. Yue, Y.D.; Yin, J.Y. Economic dynamics analysis on supply chain strategic alliance in the new construction industrialization. J. Hunan Univ. Soc. Sci. 2014, 28, 45-49.

11. Čuš-Babič, N.; Rebolj, D.; Nekrep-Perc, M.; Podbreznik, P. Supply-chain transparency within industrialized construction projects. Comput. Ind. 2014, 65, 341-353. [CrossRef]

12. Abedi, M.; Fathi, M.S.; Mirasa, A.K.; Rawai, N.M. Integrated collaborative tools for precast supply chain management. Sci. Iran. Trans. A Civ. Eng. 2016, 23, 429-448. [CrossRef]

13. Hu, M.; Jiang, Z.H.; Du, J. Platform design and transport management research of prefabricated concrete components supply chain. House Ind. 2015, 10, 41-45.

14. Zeng, T.; Qiu, K.N.; Li, Y.G. Research on digital lean construction platform of prefabricated concrete components based on supply chain. Inf. Technol. Civ. Eng. Constr. 2013, 5, 34-39.

15. Kamar, K.A.M.; Hamid, Z.A. Supply Chain Strategy for Contractor in Adopting Industrialized Building System (IBS). Aust. J. Basic Appl. Sci. 2011, 5, 2552-2557.

16. Ko, C. Production control in precast fabrication: Considering demand variability in production schedules. Can. J. Civ. Eng. 2011, 38, 191-199. [CrossRef]

17. Ko, C.; Wang, S. GA-based decision support systems for precast production planning. Autom. Constr. 2010, 19, 907-916. [CrossRef]

18. Ko, C.; Wang, S. Precast production scheduling using multi-objective genetic algorithms. Expert Syst. Appl. 2011, 38, 8293-8302. [CrossRef] 
19. Anvari, B.; Angeloudis, P.; Ochieng, W.Y. A Multi-Objective GA-based Optimization for Holistic Manufacturing, transportation and Assembly of Precast Construction. Autom. Constr. 2016, 71, 226-241. [CrossRef]

20. Shan, Y.H.; Li, Z.F. Knowledge sharing evolution game in the building supply chain for construction industrialization. J. Eng. Manag. 2015, 29, 1-5.

21. Lambert, D.M.; Cooper, M.C.; Pagh, J.D. Supply chain management: Implementation issues and research opportunities. Int. J. Logist. Manag. 1998, 9, 1-20. [CrossRef]

22. Mentzer, J.T.; DeWitt, W.; Keebler, J.S.; Min, S.; Nix, N.W.; Smith, C.D.; Zacharia, Z.G. Defining supply chain management. J. Bus. Logist. 2001, 22, 1-25. [CrossRef]

23. Houlihan, J.B. International Supply Chains: A New Approach. Manag. Decis. 1988, 26, 13-19. [CrossRef]

24. Tyndall, G.; Gopal, C.; Partsch, W.; Kamauff, J. Supercharging Supply Chains: New Ways to Increase Value Through Global Operational Excellence; John Wiley \& Sons: Hoboken, NJ, USA, 1998.

25. Ross, D.F. Competing through Supply Chain Management; Springer: Berlin, Germany, 1998.

26. Cooper, M.C.; Lambert, D.M.; Pagh, J.D. Supply Chain Management: More Than a New Name for Logistics. Int. J. Logist. Manag. 1997, 8, 1-14. [CrossRef]

27. Cooper, M.C.; Ellram, L.M.; Gardner, J.T.; Hanks, A.M. Meshing Multiple Alliances. J. Bus. Logist. 1997, 18, 67-89.

28. Cooper, M.C.; Ellram, L.M. Characteristics of Supply Chain Management and the Implication for Purchasing and Logistics Strategy. Int. J. Logist. Manag. 1993, 4, 13-24. [CrossRef]

29. Ellram, L.M.; Cooper, M.C. Supply Chain Management, Partnerships, and the Shipper-Third-Party Relationship. Int. J. Logist. Manag. 1990, 1, 1-10. [CrossRef]

30. La Londe, B.J.; Masters, J.M. Emerging logistics strategies: Blueprints for the next century. Int. J. Phys. Distrib. Logist. Manag. 1994, 24, 35-47. [CrossRef]

31. La Londe, B.J. Supply Chain Management: Myth or Reality. Supply Chain Manag. Rev. 1997, 1, 6-7.

32. Burgess, K.; Singh, P.J.; Koroglu, R. Supply chain management: A structured literature review and implications for future research. Int. J. Oper. Prod. Manag. 2006, 26, 703-729. [CrossRef]

33. Abduh, M.; Soemardi, B.W.; Wirahadikusumah, R.D. Indonesian Construction Supply Chains Cost Structure and Factors: A Case Study of Two Projects. J. Civ. Eng. Manag. 2012, 18, 209-216. [CrossRef]

34. Yeo, K.T.; Ning, J.H. Integrating supply chain and critical chain concepts in engineer-procure-construct (EPC) projects. Int. J. Proj. Manag. 2002, 20, 253-262. [CrossRef]

35. Irizarry, J.; Karan, E.P.; Jalaei, F. Integrating BIM and GIS to improve the visual monitoring of construction supply chain management. Autom. Constr. 2013, 31, 241-254. [CrossRef]

36. Xue, X.; Wang, Y.; Shen, Q.; Yu, X. Coordination mechanisms for construction supply chain management in the Internet environment. Int. J. Proj. Manag. 2007, 25, 150-157. [CrossRef]

37. Pan, N.-H.; Lee, M.-L.; Chen, S.-Q. Construction material supply chain process analysis and optimization. J. Civ. Eng. Manag. 2011, 17, 357-370. [CrossRef]

38. Parunak, H.V.; Savit, R.; Riolo, R.L. Agent-based modeling vs. equation-based modeling: A case study and users' guide. In Proceedings of the Multi-Agent Systems and Agent-Based Simulation, MABS '98, Paris, France, 4-6 July 1998; pp. 10-25.

39. Anumba, C.J.; Ugwu, O.O.; Newnham, L.; Thorpe, A. Collaborative design of structures using intelligent agents. Autom. Constr. 2002, 11,89-103. [CrossRef]

40. Pena-Mora, F.; Wang, C.Y. Computer-supported collaborative negotiation methodology. J. Comput. Civ. Eng. 1998, 12, 64-81. [CrossRef]

41. Xue, X.; Li, X.; Shen, Q.; Wang, Y. An agent-based framework for supply chain coordination in construction. Autom. Constr. 2005, 14, 413-430. [CrossRef]

42. Tesfatsion, L. Agent-based Computational Economics: A constructive approach to economic theory. In Handbook of Computational Economics; Elsevier: Amsterdam, The Netherlandsm, 2005; Volume 2, p. 55.

43. Marceau, J.; Houghton, J.; Toner, P.; Manley, K.; Gerasimou, E.; Cook, N. Mapping the Building and Construction Product System in Australia; Commonwealth Department of Industry, Science and Resources: Sydney, Australia, 1999.

44. Tremblay, V.J.; Tremblay, C.H. Quantity and Price Competition in Static Oligopoly Models. New Perspect. Ind. Organ. 2012. [CrossRef] 
45. Aloini, D.; Dulmin, R.; Mininno, V.; Ponticelli, S. Supply Chain Management: A Review of Implementation Risks in the Construction Industry. Bus. Process Manag. J. 2012, 18, 735-761. [CrossRef]

46. Zhang, X.; Skitmore, M. Industrialized housing in China: A coin with two sides. Int. J. Strateg. Prop. Manag. 2012, 16, 143-157. [CrossRef] 